\title{
Evaluation and Optimization of Agro-industrial Wastes for Conidial Production of Metarhizium anisopliae isolates under Solid State Fermentation
}

\author{
Abiy Tewelde* and Tesfaye Alemu \\ Department of Microbial, Cellular and Molecular Biology, College of Natural Sciences, Addis Ababa \\ University, P.O. Box 1176, Addis Ababa, Ethiopia (*abiy2001ec@yahoo.com).
}

\begin{abstract}
Metarhizium anisopliae is known to cause high level of epizootics for more than 200 insect species in versatile agro-ecologies. Concerns on environmental pollution and resistance development to chemical insecticides need environmentally safe and economically viable approaches. Therefore, here we investigate a cheap and large scale industrial production of virulent enthomopathogenes on agricultural wastes. Three Metarhizium anisopliae isolates were grown on agricultural wastes to evaluate their conidia production potential under Solid state fermentation (SSF) technique. Coffee husk, tea waste, wheat bran and vegetable wastes were used as substrates to determine their capability for maximum conidiation of the isolates. Among these, vegetable wastes were the best media to yield $5.80 \pm 0.72\left(10^{7}\right), 4.44 \pm 0.55\left(10^{7}\right)$ and $5.58 \pm 0.66\left(10^{7}\right)$ conidia/gram of substrate under quantitative assessment for isolate AUMI1, AUMI2 and AUMI3 respectively, at $60 \%$ moisture content. Statistically on two sample t-test vegetable wastes shows significant difference in conidia production when compared to $2 \mathrm{~mm}$ and $4 \mathrm{~mm}$ sized coffee husk used as substrates. The optimization for temperature indicated that all substrates supported their maximum conidia yield within $27-30^{\circ} \mathrm{C}$ range of temperature. The $3.5 \mathrm{pH}$ value used in the present study for optimization was best favored only for coffee husk as

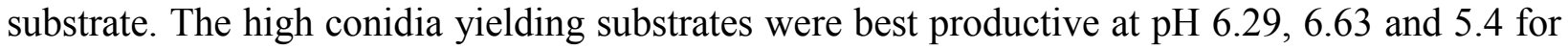
vegetable wastes, wheat bran and tea waste, respectively. All isolates incubated on wheat bran was highly productive under sufficient exposure to light. AUMI1 produced high conidia under exposure to light while the higher yield of AUMI2 and AUMI3 was produced under dark condition on vegetable wastes. Therefore, as successful microbial control of insect pests depends on large scale and cheap industrial productivity, cultivation on vegetable wastes and wheat bran under SSF can be a plausible solution.
\end{abstract}

Keywords: Metarhizium anisopliae, Inoculation, Optimization, Substrate, Conidia.

\section{INTRODUCTION}

The origins of microbial pest control date back to the early $19^{\text {th }}$ century, when the Italian scientist Agostino Bassi studied white muscardine disease on silkworms (Bombyxmori). He identified Beauveria bassiana as the cause of the disease (Yadav and Neeraj, 2012; Chinnadurai and Ganesh, 2013). His discovery was a major milestone in microbial pest control technology which triggers the use of entomopathogenic fungi, such as Metarhizium anisopliae as highly active insect pest under laboratory conditions (Chinnadurai and Ganesh, 2013). The first attempt to control pest with a fungal agent was carried out in Russia in 1888, when the fungus now known 
as $M$. anisopliae was mass produced on beer mash and sprayed in the field for control of the beetle weevil Cleonus Punctiventris (Lord, 2005).

In the last years entomopathogenic fungi biology and ecology have been studied more and the attention of scientists was focused mainly on the fungi genus Beauveria and Metarhizium since they attack broad spectrum of insects (Mudrončeková et al., 2013). They are often reported as causing high levels of epizootics in nature and are the most versatile and eco-friendly biological control agents. These fungi contain a heterogeneous group of over 100 genera with approximately 750 species, notified from different insects and many of them are proved to be highly potent to insect pests. Among these Metarhizium spp., Beauveria spp., Nomuraearileyi, Verticillium lecanii and Hirsutellaspp are highly known (Jitendra et al., 2012).

M. anisopliae is the second most widely exploited entomopathogenic fungi in bio-control trials next to $B$. bassiana (Jitendra et al., 2012) and it is known to attack more than 200 inset species belonging to different orders (Peng et al., 2009; Jitendra et al., 2012; Chen et al., 2014). This has been responsible for a substantial increase in interest for large scale production of good quality inoculums of the fungus for field application sake of the bio control program.

Conidial Biomass production from Agricultural wastes is inexpensive. The annually produced wastes from worldwide Food, Agricultural and Forestry industries are causes of serious environmental, health and disposal management problems (Orzua et al., 2009; Zuriash Mamo and Tesfaye Alemu, 2012). Wastes like sugarcane, fruit bagsse and peels generated in the beverages and juice industries, coffee pulp obtained from coffee industries, sawdust from wood industries and husks from cereals are abundant. Therefore, utilization of these wastes for large scale mycoinsecticide conidia production would be economically viable despite of its role in controlling environmental pollution.

Different studies have been conducted so far, for mass production of conidia using agricultural wastes under solid state and submerged fermentation. Wheat straw, tea waste, vegetable waste, coffee husk and barley bran has been evaluated to determine optimal conditions for conidia production of Trichoderma (Zuriash Mamo and Tesfaye Alemu, 2012). Sugarcane bagasse, orange peel, wheat straw, cotton seeds, castor been and rice husk were used alone as carbon source for the production of single cell protein (Khan and Dahot, 2010) Kitchen wastes are used for bio pesticide production under solid state fermentation (Zhang et al., 2013). 
According to $\mathrm{Wu}$ et al. (2010), different isolates germination, spore production and virulence is associated with the appropriate concentrations of nitrogen and carbon in the culture medium. Nutritional requirements of the entomopathogenic fungi could vary with the fungal species and even the fungal strain under consideration. Generally a fungus requires oxygen, water, source of carbon, and organic or inorganic nitrogen besides minerals that play a major role in growth, pathogenicity and novel metabolite production. Therefore, successful microbial insect pest control also depends on easy and cheap mass production of the virulent microbial agents in laboratory and in industry as well (Sahayaraj and Namasivayam, 2008).

Production of locally isolated entomopathogenic fungi under suitable media for large scale application has not yet been studied. Therefore, in the present study isolates of $M$. anisopliae are screened for mass production of conidia under laboratory scale solid state fermentation using different substrates.

\section{MATERIAL AND METHODS}

\subsection{Source of Metarhizium Isolates}

Three M. anisopliae isolates were obtained from Ababa University (AAU), Department of Microbial, Cellular and Molecular Biology; Mycology Laboratory Culture collection. All Metarhizium stains used in this study were isolated from insect cadavers of grasshopper, beetles and locusts from soil samples of south western Ethiopia. The acronyms given to the isolates were derived from initial letters of the university's name and the genus name of the isolate followed by the letter "I" to represent isolate and number to differentiate which isolate number is it.

For laboratory study the fungal isolates was first grown on Sabouraud dextrose agar (SDA) medium. The medium was sterilized at $121^{\circ} \mathrm{C}$ for 15 minutes in autoclave, poured to sterilized plates in a hood, cooled and inoculated with pure culture of the fungal isolates on their respective plates under aseptic conditions. Followed the inoculation plates were allowed to incubate at $27^{\circ} \mathrm{C}$ for 14 days (Holder and Keyhani, 2005; Masoud et al., 2013). After complete growth the fungal cultures were kept in refrigeration temperature $\left(4^{0} \mathrm{C}\right)$ for further study.

\subsection{Preparation of conidia suspension:-}

Conidia inoculum for solid state media culture were obtained from 14 days old sporulated culture on Sabouraud dextrose agar (SDA) plates at $27^{\circ} \mathrm{C}$. Conidia were harvested using sterile $0.02 \%$ $(\mathrm{v} / \mathrm{v})$ Tween 80 solution by flooding the plate and scrapping the spores with hockey glass stick to 
remove the spores from the mycelial mat of the culture. The suspended spores of Metarhizium were collected in to their respective conical flasks and filtered through three layers of cheese cloth. Conidial concentrations were determined by direct counting using Heamocytometer under light microscopy (Wang and Powell, 2002).

\subsection{Procurement of agricultural wastes for conidia production}

The agricultural wastes used in this study were collected from different areas in Addis Ababa City administration and from college students' cafeteria. All the wastes were initially clean to remove debris and washed with water followed by drying under shade condition. Subsequently, all the wastes were ground in to powder using a Hammer beater mill (Muhammad et al., 2012). The powdered form of each waste was stored in plastic bags for subsequent study.

\subsection{Solid state fermentation using agricultural waste substrates for conidia production}

Ten gram $(10 \mathrm{~g})$ of agricultural waste powder was weighed for a single inoculum experiment and autoclaved at $121^{\circ} \mathrm{C}$ for 15 minutes in a heat resistant plastic bag (Pham et al., 2010). After sterilization each substrate was transferred in to aseptically sterilized $20 \times 30 \mathrm{~cm}^{2}$ sized plastic bags under microbiologically safe techniques and $1 \mathrm{ml}$ of seeding inoculum with conidial concentration of $1.0 \times 10^{5}$ onidia/ml was sprayed using hand sprayer. The samples were incubated in light transparent incubator at temperature $27^{0} \mathrm{C}$ for two weeks period of time. Within this form of solid state fermentation technique all high conidial biomass producing wastes were evaluated to optimize conditions such as temperature, $\mathrm{pH}$, moisture content, incubation period, inoculum concentration, inoculum size and the effect of light for maximum conidial productivity. All experiment in this research finding was three times replicated.

\subsection{Conidia harvesting from the substrates medium}

From each 14 days old conidiated culture $1 \mathrm{~g}$ was weighed and suspended in $20 \mathrm{ml}$ of $0.05 \%$ Tween 80 solution containing beaker. To dissociate conidia clamps the beaker was vigorously agitated for 3-5 minutes by hand. The suspensions were then filtered through three layered cheese close and conidia concentration was evaluated by counting under Heamocytometer. Result of the count was calculated arithmetically to know the total spore count in $1 \mathrm{~g}$ of substrate.

\subsection{Conidia Counting}

Estimation of the amount of conidia suspension in stock concentration containing bottle was carried out using a standard formula. Serial dilution were prepared from the original suspension by drawing $1 \mathrm{ml}$ of spore concentrated solution from the original suspension and transfer it to $9 \mathrm{ml}$ 
distilled water containing test tube to dilute the spore concentration by a factor of 10 . The process was repeated many times as necessary to achieve countable number of spores over the grids. Using a micro pipette 20 microliters of spore suspension were sucked and loaded to a clean cover slip affixed Heamocytometer. Chambers of the Heamocytometer were allowed to fill via capillary action carefully not to overfill or under fill it. There are four big squares in the Heamocytometer with 16 smaller squares in each, all the cells in the four corner squares of each big square were counted by placing the Heamocytometer chamber on microscope stage. Numbers of conidia count on the squares of the grids were recorded. Cell concentration per milliliter was calculated using standard formula. Stock cell concentration per milliliter and conidia concentration per gram of substrate were arithmetically calculated respectively.

\subsection{Spore Viability}

The viability of conidia was determined by spread plating of $1 \mathrm{ml}$ of conidial suspension (titrated to $1 \times 10^{3}$ conidia/ ml) on Sabouraud dextrose agar. Spore was inoculated on eight centimeter $(8 \mathrm{~cm})$ in diameter plates and examined after 12-18 hours. Spore germination was held by placing 3- separate drops of lactophenol cotton blue, sterile microscopic cover slips were placed over the stained droplets for examination. The proportion of viable conidia was determined by examining 100 spores in each of the three different fields of view at $400 \mathrm{X}$ magnification with a compound microscope. Proportion of spores that possessed a distinct germ tube, as defined by germ tube lengths that are two times the diameter of the spore are viable as stated on (Philip et al., 2011 and Fatima et al., 2013).

\subsection{Optimization of Moisture Content for Conidia Production}

Moisture content of the agricultural wastes was determined by oven drying method as stated on (Rao et al., 2006). Labeled small glass bottles were placed in an oven at approximately $80^{\circ} \mathrm{C}$ for about two hours to ensure that they are completely dry. The bottles weighed and recorded after allowed cooling at room temperature with cover lids put on. Ten $(10 \mathrm{~g})$ gram of substrate from each agricultural waste were added to their respective glass bottles and make a note of the new weight for wet weight of the substrates by replacing the cover lids.

The container bottles with substrates were placed back in to the oven at $60^{\circ} \mathrm{C}$ for one to six hours until constant weight of the dry weight is found. Finally moisture content of the substrates was calculated based on wet-weight basis and express it as a percentage to one decimal place, using the following formula (Rao et al., 2006). 


$$
\text { Moisture content }(\% \mathrm{wb})=\frac{\text { wetweight }- \text { dryweight }}{\text { wetweight }} * 100
$$

Based on the formula moisture content of each agricultural waste was adjusted to $35 \%, 45 \%$, $60 \%$ and $80 \%$ respectively. All the determined moisture levels were evaluated for maximum conidial production capability of M.anisopliae isolates under solid state fermentation (SSF).

\subsection{Optimization of Temperature for Conidia Production}

Metarhizium isolate inoculated agricultural waste Medias prepared to incubate at $24^{0} \mathrm{C}, 27^{0} \mathrm{C}$ and $30^{\circ} \mathrm{C}$ at high productive moisture level with respect to isolate type. Each of the substrate containing plastic bags were sprayed with $1 \mathrm{ml}$ of $1 \times 10^{5}$ conidia concentration and tie up with rubber band to prevent air blow and contamination in the incubator. Aeration was allowed to the culture via two $1 \mathrm{~cm}$ sized holes provided at the top of the plastic bag. The culture was incubated for 14 days before spore sample were taken to numerate under heamocytometer (Pham et al., 2010).

\subsection{Optimization of $\mathbf{P H}$ for Conidia Production}

Ten $(10 \mathrm{~g})$ gram of substrates from each agricultural waste was weighed to examine under different $\mathrm{pH}$ levels. The $\mathrm{pH}$ was adjusted to 3.5, 4.5 and 5.5 using $1 \mathrm{~N}$ of $\mathrm{HCl}$ (hydrochloric acid) and $\mathrm{NaOH}$ (sodium hydroxide). The media was autoclaved at $121^{\circ} \mathrm{C}$ for $15 \mathrm{~min}$ and transferred to their respective plastic bags under aseptically safe condition. Substrates are allowed to cool and $1 \mathrm{ml}$ of $\left(1 \times 10^{5}\right)$ conidia concentration of each isolate was sprayed to their respective plastic bags followed by incubation at $27^{0} \mathrm{Cfor} 14$ days. The conidia yield was determined by heamocytometer count (Zuriash Mamo and Tesfaye Alemu, 2012).

\subsection{Optimization of Inoculum Concentration}

The sterilized substrates in the plastic bags were adjusted at the best moisture level. Conidial concentrations of $1 \times 10^{3}, 1 \times 10^{4}$ and $1 \times 10^{5}$ were prepared in different flasks from stock concentration of each isolate. The formula used for conidial concentration preparation was as indicated in insect pathology manual.

$$
x=\frac{\text { Required concentration } * \text { Final volume Neeed }}{\text { Counted concentration }}
$$

Where, $\mathrm{X}=$ number of $\mathrm{ml}$ of spores from original suspension to be added to the distilled water. The prepared conidial concentrations were sprayed into their respective substrates arranged. Each of the waste substrates was evaluated by all the prepared concentration levels with $1 \mathrm{ml}$ of 
inoculum size and incubated for 14 days. Conidial harvest and numeration were conducted by taking $1 \mathrm{~g}$ of conidiated substrate.

\subsection{Effect of light on conidia production}

$10 \mathrm{~g}$ of agricultural waste substrates for each plastic bag were autoclaved at $121^{\circ} \mathrm{C}$ for $15 \mathrm{~min}$. sterilized substrates inoculated with $1 \mathrm{ml}$ of $\left(1 \times 10^{5}\right.$ conidia/ $\left.\mathrm{ml}\right)$ were incubated under opaque and light transparent plastic bags both with aeration pores at the top. The cultures were incubated for 14 days. Finally, $1 \mathrm{~g}$ of conidiated substrate was suspended, filtered and numerated by heamocytometer.

\subsection{Data analysis}

All the data were statistically analyzed using SPSS (version 20). Substrates potential to support growth of $M$. anisopliae isolates were statistically compared using Analysis of Variance (ANOVA). Conidia production results of each substrate with respect to isolate type were expressed as Mean \pm Standard Error of Mean (SEM). Mean difference of two isolates conidia yield concentration on different substrates were computed using two sample t-Test. For all experiments, a probability level of $\mathrm{p} \leq 0.05$ was considered as statistically significant.

\section{RESULTS}

\subsection{Evaluation of agricultural wastes for conidia production}

Substrates such as three different sizes of coffee husk, tea waste, wheat bran and vegetable wastes were used to evaluate their support to grow entomopathogenic fungi $M$. anisopliae isolates. Among the substrates tested, vegetable wastes support high conidial productivity of AUMI1, AUMI2 and AUMI3 with $4.90 \pm 0.33 \times 10^{7}, 3.74 \pm 0.57 \times 10^{7}$ and $3.62 \pm 0.44 \times 10^{7}$ conidia/gram of substrate respectively. Tea waste substrate produces the second highest conidial yield for AUMI1 and AUMI2 $1.41 \times 10^{7} \pm 0.16 \times 10^{7}$ and $1.50 \times 10^{7} \pm 0.14 \times 10^{7}$ conidia/gram respectively. The second maximum conidial yield for AUMI3 was harvested from wheat bran.

Vegetable wastes favored maximum conidial productivity of $M$. anisopliae isolates when the fungal isolates were treated at $27^{\circ} \mathrm{C}$ for 14 days of incubation under solid state fermentation (Table 1). The lowest conidial productivity was overall recorded on coffee husk, but the least productive substrate for AUMI1 and AUMI3 was record by $2 \mathrm{~mm}$ size coffee husk which gives $0.20 \times 10^{7} \pm 0.02 \times 10^{7}$ and $0.33 \times 10^{7} \pm 0.04 \times 10^{7}$ of conidia/gram of substrate respectively. Least conidial harvest of AUMI $0.36 \times 10^{7} \pm 0.07 \times 10^{7}$ was produced by $4 \mathrm{~mm}$ size coffee husk. 
Table 1. Conidia yields of M. anisopliae isolates on different agricultural wastes.

\begin{tabular}{|llll|}
\hline \multirow{2}{*}{$\begin{array}{l}\text { Substrates } \\
\end{array}$} & $\begin{array}{l}\text { Mean } \pm \text { SEM of conidia count of substrates at (x10 } \\
\text { after 14 days of incubation }\end{array}$ & \\
\cline { 2 - 4 } & Metarhizium anisopliae isolates & \\
\cline { 2 - 4 } & AUMI1 & AUMI & AUMI3 \\
\hline 1 mm Coffee husk & $0.83 \pm 0.08$ & $1.06 \pm 0.18$ & $0.60 \pm 0.07$ \\
\hline 2mm Coffee husk & $0.20 \pm 0.02$ & $0.46 \pm 0.05$ & $0.33 \pm 0.04$ \\
\hline $4 \mathrm{~mm}$ Coffee husk & $0.62 \pm 0.15$ & $0.36 \pm 0.07$ & $0.42 \pm 0.08$ \\
\hline Tea waste & $1.41 \pm 0.16$ & $1.50 \pm 0.14$ & $0.89 \pm 0.10$ \\
\hline Wheat bran & $1.14 \pm 0.13$ & $1.38 \pm 0.15$ & $1.09 \pm 0.10$ \\
\hline Vegetable waste & $4.90 \pm 0.33$ & $3.74 \pm 0.57$ & $3.61 \pm 0.44$ \\
\hline
\end{tabular}

Note: Mean calculated from three replications, all the isolate cultures on each substrate was incubated at $27^{\circ}$ for 14 days.

AUMI1 gives the maximum conidial yield on vegetable waste from the tested isolates and the lowest conidia yield were recorded by AUMI1 on $2 \mathrm{~mm}$ size coffee husk. Based on two sample tTest statistical analysis mean conidia yield of AUMI1 was significantly higher on vegetable waste than on $2 \mathrm{~mm}$ size coffee husk. The same was true for AUMI2 on vegetable waste than on $4 \mathrm{~mm}$ size coffee husk and AUMI3 on vegetable waste and on $2 \mathrm{~mm}$ size coffee husk respectively. The mean conidia yield of AUMI2 and AUMI3 on vegetable wastes were significantly different form conidia yields on $4 \mathrm{~mm}$ and $2 \mathrm{~mm}$ particle sized coffee husk, with $\mathrm{t}(11.35)=3.38^{*} 10^{7}, \mathrm{p}=0$, and $\mathrm{t}(11.23)=3.28 * 10^{7}, \mathrm{p}=0$ respectively (Table 1$)$.

Table 2. The effect of moisture on conidia yield of $M$. anisopliae Isolates at $27^{0}{ }_{C}$ after 14 days.

\begin{tabular}{|c|c|c|c|c|c|c|c|c|c|c|c|c|}
\hline \multirow[t]{3}{*}{ Substrates } & \multicolumn{12}{|c|}{$\begin{array}{l}\text { Mean } \pm \text { SEM of conidia count at (X10 Conidia/gram) for moisture content optimization after } \\
14 \text { days of incubation }\end{array}$} \\
\hline & \multicolumn{4}{|c|}{ AUMI1 } & \multicolumn{4}{|c|}{ AUMI2 } & \multicolumn{4}{|c|}{ AUMI3 } \\
\hline & $35 \%$ & $45 \%$ & $60 \%$ & $80 \%$ & $35 \%$ & $45 \%$ & $60 \%$ & $80 \%$ & $35 \%$ & $45 \%$ & $60 \%$ & $80 \%$ \\
\hline $\begin{array}{l}4 \mathrm{~mm} \text { size } \\
\text { coffee husk }\end{array}$ & $\begin{array}{l}0.37 \pm \\
0.18^{(a)}\end{array}$ & $\begin{array}{l}0.37 \pm \\
0.17^{(\mathrm{a})}\end{array}$ & $\begin{array}{l}1.01 \pm \\
0.52^{(\mathrm{a})}\end{array}$ & & $\begin{array}{l}0.37 \pm \\
0.20^{(\mathrm{a})}\end{array}$ & $\begin{array}{l}0.40 \pm \\
0.21^{(\mathrm{a})}\end{array}$ & $\begin{array}{l}0.30 \pm \\
0.09^{(\mathrm{a})}\end{array}$ & & & & $\begin{array}{l}0.33 \pm \\
0.10^{(\mathrm{a})}\end{array}$ & $\begin{array}{l}0.57 \pm \\
0.17^{(\mathrm{a})}\end{array}$ \\
\hline $\begin{array}{l}2 \mathrm{~mm} \mathrm{~s} \\
\text { coffee }\end{array}$ & $\begin{array}{l}0.18 \pm \\
0.04^{(a)}\end{array}$ & $\begin{array}{l}0.26 \pm \\
0.02^{(\mathrm{a})}\end{array}$ & $\begin{array}{l}0.24 \pm \\
0.02^{(\mathrm{a})}\end{array}$ & $\begin{array}{l}0.14 \pm \\
0.02^{(\text {(a) }}\end{array}$ & $\begin{array}{l}0.53 \pm \\
0.10^{(a)}\end{array}$ & $\begin{array}{l}0.39 \pm \\
0.09^{(\text {a) }}\end{array}$ & $\begin{array}{l}0.57 \pm \\
0.10^{\text {(a) }}\end{array}$ & & & & $\begin{array}{l}0.40 \pm \\
0.02^{(\text {a) }}\end{array}$ & $\begin{array}{l}0.20 \pm \\
0.05^{\text {(a) }}\end{array}$ \\
\hline $\begin{array}{l}1 \mathrm{~mm} \\
\text { coffe }\end{array}$ & $\begin{array}{l}0.96 \pm \\
0.12^{(\text {a) }}\end{array}$ & $\begin{array}{l}0.95 \pm \\
0.09^{(\text {b) }}\end{array}$ & $\begin{array}{l}0.95 \pm \\
0.18^{(a)}\end{array}$ & & & $\begin{array}{l}1.39 \pm \\
0.20^{\text {(a) }}\end{array}$ & & & & & $\begin{array}{l}0.68 \pm \\
0.15^{(\text {a) }}\end{array}$ & $\begin{array}{l}0.27 \pm \\
0.04^{\text {(a) }}\end{array}$ \\
\hline Tea waste & $\begin{array}{l}1.07 \pm \\
0.07^{(\mathrm{a})}\end{array}$ & $\begin{array}{l}0.96 \pm \\
0.18^{(\mathrm{b})}\end{array}$ & $\begin{array}{l}1.55^{ \pm} \\
0.37^{(\mathrm{a})}\end{array}$ & $\begin{array}{l}2.05 \pm \\
0.10^{(\mathrm{c})}\end{array}$ & $\begin{array}{l}0.94 \pm \\
0.07^{(a)}\end{array}$ & & $\begin{array}{l}1.89 \pm \\
0.12^{\text {(a) }}\end{array}$ & $\begin{array}{l}1.90 \pm \\
0.23^{(\mathrm{a}, \mathrm{c})}\end{array}$ & & $\begin{array}{l}1.32 \pm \\
0.15^{(\mathrm{a}, \mathrm{b})}\end{array}$ & $\begin{array}{l}0.83 \pm \\
0.24^{(\text {a) }}\end{array}$ & $\begin{array}{l}0.63 \pm \\
0.05^{\text {(a) }}\end{array}$ \\
\hline Wheat bran & $\begin{array}{l}1.25 \pm \\
0.34^{\text {(a) }}\end{array}$ & $\begin{array}{l}1.46 \pm \\
0.09^{(\text {b) }}\end{array}$ & $\begin{array}{l}1.01 \pm \\
0.26^{(a)}\end{array}$ & $\begin{array}{l}0.82 \pm \\
0.20^{(\text {a) }}\end{array}$ & $\begin{array}{l}1.56 \pm \\
0.23^{(a)}\end{array}$ & $\begin{array}{l}1.59 \pm \\
0.10^{\text {(a) }}\end{array}$ & $\begin{array}{l}1.43 \pm \\
0.56^{(\mathrm{a})}\end{array}$ & $\begin{array}{l}0.95 \pm \\
0.08^{(a)}\end{array}$ & & $\begin{array}{l}1.07 \pm \\
0.27^{(\mathrm{a}, \mathrm{b}} \mathrm{b}\end{array}$ & $\begin{array}{l}1.10 \pm \\
0.09^{(\text {a) }}\end{array}$ & $\begin{array}{l}0.99 \pm \\
0.13^{\text {(a) }}\end{array}$ \\
\hline $\begin{array}{l}\text { Vegetable } \\
\text { waste }\end{array}$ & $\begin{array}{l}4.34 \pm \\
1.08^{(\mathrm{b})}\end{array}$ & $\begin{array}{l}4.56 \pm \\
0.09^{(\mathrm{c})}\end{array}$ & $\begin{array}{l}5.80 \pm \\
0.72^{(\text {b) }}\end{array}$ & $\begin{array}{l}4.49 \pm \\
0.08^{(b)}\end{array}$ & $\begin{array}{l}3.53 \pm \\
2.29^{(\text {a) }}\end{array}$ & $\begin{array}{l}3.80 \pm \\
0.59^{(\mathrm{b})}\end{array}$ & $\begin{array}{l}4.44 \pm \\
0.55^{(\mathrm{b})}\end{array}$ & $\begin{array}{l}3.19 \pm \\
0.95^{(\mathrm{c})}\end{array}$ & $\begin{array}{l}2.98 \pm \\
0.46^{(b)}\end{array}$ & $\begin{array}{l}2.38 \pm \\
0.78^{(b)}\end{array}$ & $\begin{array}{l}5.59 \pm \\
0.66^{(\mathrm{b})}\end{array}$ & $\begin{array}{l}3.52 \pm \\
0.34^{(b)}\end{array}$ \\
\hline
\end{tabular}

Note: Means in the same column designated by different letters are significantly different, (a-c), at $\mathrm{p} \leq 0.05$. 


\subsection{Effect of Moisture Content on Conidia Production of M.anisopliae Isolates}

The optimum moisture content for conidia production of each isolate varies within and between substrate types (Table 2). The optimum moisture content for all isolates in the substrate of vegetable waste was $60 \%$ and the conidia count recorded was significantly high among the rest of the substrates. The result in the present study revealed that the total conidia harvest of each strain with respect to competing moisture contents on substrates of $2 \mathrm{~mm}$ and $4 \mathrm{~mm}$ size coffee husks is lower than any other substrate used in this study (Table 2). AUMI2, AUMI1 and AUMI3 gives their maximum conidia productivity $\left(0.40 \times 10^{7} \pm 0.21 \times 10^{7}, 1.01 \times 10^{7} \pm 0.52 \times 10^{7}\right.$, and $0.57 \times 10^{7} \pm 0.17 \times 10^{7}$ conidia/gram of substrate) at $45 \%, 60 \%$ and $80 \%$ moisture content of $4 \mathrm{~mm}$ size coffee husk, respectively.

There was a gradual increment in the conidia count of AUMI1 and AUMI2 as the effect of moisture content increases from 35 to $80 \%$ using tea waste as substrate. However, conidia count of AUMI3 is higher at 45\% moisture. Therefore, tea waste specially provides its highest conidia count at $80 \%$ of moisture content for the first two isolates. Wheat bran give the maximum conidia yield of AUMI1 and AUMI2at 45\% whereas AUMI3 at 35\% of moisture content, respectively.

The mean conidia yield of AUMI1 at vegetable waste $\left(M=5.81 * 10^{7}, S D=1.25^{*} 10^{7}, N=\right.$ 3) was significantly increased from $2 \mathrm{~mm}$ size coffee husk $\left(M=2.57 * 10^{6}, S D=3.79 * 10^{5}, N=3\right)$ $\mathrm{t}(4)=5.55^{*} 10^{7}, \mathrm{p}=0.002$. The mean conidia yield of AUMI2 at vegetable waste $\left(M=4.45^{*} 10^{7}\right.$, $\left.S D=9.47^{*} 10^{6}, N=3\right)$ was significantly increased from $4 \mathrm{mmsize}$ coffee husk $\left(M=4.05^{*} 10^{6}, S D\right.$ $\left.=3.60 * 10^{6}, N=3\right) \mathrm{t}(2.57)=4.04 * 10^{7}, \mathrm{p}=0.01$.

The mean conidia yield of AUMI3 at vegetable waste $\left(M=5.59 * 10^{7}, S D=1.15^{*} 10^{7}, N=\right.$ 3) was significantly increased from $2 \mathrm{~mm}$ size coffee husk $\left(M=3.63^{*} 10^{6}, S D=5.80^{*} 10^{5}, N=3\right)$ $\mathrm{t}(4)=5.22 * 10^{7}, \mathrm{p}=0.001$.

\subsection{Effect of Temperature on Conidia Production of M. anisopliae Isolates}

Incubation temperature markedly affects conidia yield as it can be noticed in table 3 . The majority of the isolates in all substrate types the optimal temperature for high conidia productivity was $30^{\circ} \mathrm{C}$ after 14 days of incubation. AUMI1 and AUMI2 got their maximum conidia yield of $2.09 \times 10^{7} \pm 0.25 \times 10^{7}$ and $1.28 \times 10^{7} \pm 0.27 \times 10^{7}$ conidia/gram of substrate, respectively when incubated for 14 days at $30^{\circ} \mathrm{C}$ using coffee husk as a substrate. Whereas the 
optimum conidia yield for AUMI3 on coffee husk were found at $24^{0} \mathrm{C}$ after 14 days of incubation.

Table 3. Effect of temperature on conidial yield of isolates at different substrates.

\begin{tabular}{|c|c|c|c|c|c|c|c|c|c|}
\hline \multirow[t]{4}{*}{ Substrates } & \multicolumn{9}{|c|}{$\begin{array}{c}\text { Mean } \pm S E M \text { of conidia count }\left(X 10^{7} \text { conidia/gram)for temperature }\right. \\
\text { optimization after } 14 \text { days of incubation }\end{array}$} \\
\hline & \multicolumn{9}{|c|}{ Metarhizium anisopliae Isolates } \\
\hline & \multicolumn{3}{|c|}{ AUMI1 } & \multicolumn{3}{|c|}{$A U M I 2$} & \multicolumn{3}{|c|}{ AUMI3 } \\
\hline & $24^{0} \mathrm{C}$ & $27^{0} \mathrm{C}$ & $30^{0} \mathrm{C}$ & $24^{0} \mathrm{C}$ & $27^{0} \mathrm{C}$ & $30^{0} \mathrm{C}$ & $24^{0} \mathrm{C}$ & $27^{0} \mathrm{C}$ & $30^{\circ} \mathrm{C}$ \\
\hline Coffee & $1.14 \pm$ & $1.15 \pm$ & $2.09 \pm$ & $0.97 \pm$ & $0.81 \pm$ & $1.28 \pm$ & $1.22 \pm$ & $0.96 \pm$ & $1.19 \pm$ \\
\hline husk & $0.03^{\mathrm{a}}$ & $0.24^{\mathrm{a}}$ & $0.25^{\mathrm{b}}$ & $0.13^{\mathrm{c}}$ & $0.06^{\mathrm{c}}$ & $0.27^{\mathrm{c}}$ & $0.06^{\mathrm{d}}$ & $0.18^{\mathrm{d}}$ & $0.04^{\mathrm{d}}$ \\
\hline Wheat & $2.04 \pm$ & $0.57 \pm$ & $3.23 \pm$ & $1.73 \pm$ & $1.22 \pm$ & $1.79 \pm$ & $2.86 \pm$ & $1.10 \pm$ & $3.04 \pm$ \\
\hline bran & $0.24^{\mathrm{a}}$ & $0.33^{\mathrm{b}}$ & $0.05^{\mathrm{a}}$ & $0.28^{\mathrm{c}}$ & $0.13^{\mathrm{c}}$ & $0.30^{\mathrm{c}}$ & $0.31^{\mathrm{d}}$ & $0.33^{\mathrm{d}}$ & $0.91^{\mathrm{d}}$ \\
\hline \multirow[t]{2}{*}{ Tea waste } & $0.48 \pm$ & $0.70 \pm$ & $1.10 \pm$ & $0.77 \pm$ & $0.81 \pm$ & $0.81 \pm$ & $0.76 \pm$ & $1.43 \pm$ & $0.82 \pm$ \\
\hline & $0.03^{\mathrm{a}}$ & $0.12^{\mathrm{a}}$ & $0.04^{\mathrm{b}}$ & $0.04^{\mathrm{c}}$ & $0.07^{\mathrm{c}}$ & $0.10^{\mathrm{c}}$ & $0.28^{\mathrm{d}}$ & $0.28^{\mathrm{d}}$ & $0.05^{\mathrm{d}}$ \\
\hline \multirow{2}{*}{$\begin{array}{l}\text { Vegetable } \\
\text { waste }\end{array}$} & $4.03 \pm$ & $5.05 \pm$ & $3.79 \pm$ & $2.29 \pm$ & $2.67 \pm$ & $2.97 \pm$ & $2.94 \pm$ & $3.69 \pm$ & $4.60 \pm$ \\
\hline & $0.40^{\mathrm{a}}$ & $0.43^{\mathrm{a}}$ & $0.48^{\mathrm{a}}$ & $0.11^{\mathrm{c}}$ & $0.23^{\mathrm{c}}$ & $0.16^{\mathrm{c}}$ & $0.39^{\mathrm{d}}$ & $0.41^{\mathrm{d}}$ & $0.94^{\mathrm{d}}$ \\
\hline
\end{tabular}

Note: Means in the same row along the substrate within Isolate type designated by different letters are significantly different, $(\mathrm{a}-\mathrm{d})$, at $\mathrm{p} \leq 0.05$.

Among the substrate types examined vegetable wastes for AUMI2 and AUMI3 2.97 $\times 10^{7} \pm 0.16 \times 10^{7}$ and $4.60 \times 10^{7} \pm 0.94 \times 10^{7}$ conidia/gram of substrate supported for maximum conidia yield at $30^{0} \mathrm{C}$. However, it also supported AUMI1 $\left(5.05 \times 10^{7} \pm 0.43 \times 10^{7}\right.$ conidia/gram of substrate) for maximum conidia yield at $27^{\circ} \mathrm{C}$. The optimum temperature for AUMI1 and AUMI2 grown on tea waste substrate was $30^{\circ} \mathrm{C}$. Among the isolates tea waste at $27^{0} \mathrm{C}$ favored higher conidia yield for AUMI3 (1.43 X10 $\pm 0.28 \times 10^{7}$ conidia/gram of substrate).

The mean conidia yield of AUMI1 on vegetable waste $\left(M=5.05 * 10^{7}, S D=7.41 * 10^{6}, N=\right.$ 3) was significantly higher from tea waste $\left(M=1.10^{*} 10^{7}, S D=7.01 * 10^{5}, N=3\right), \mathrm{t}(4)=$ $3.95^{*} 10^{7}, \mathrm{p}=0.001$. The mean conidia yield of AUMI2 on vegetable waste $\left(M=2.97 * 10^{7}, S D=\right.$ $\left.2.71 * 10^{6}, N=3\right)$ was significantly higher from tea waste $\left(M=8.07 * 10^{6}, S D=1.19 * 10^{6}, N=3\right)$, $\mathrm{t}(2.74)=2.17 * 10^{7}, \mathrm{p}=0.002$. The mean conidia yield of AUMI3 on vegetable waste $(M=$ $\left.4.60^{*} 10^{7}, S D=1.63 * 10^{7}, N=3\right)$ was significantly higher from coffee husk $\left(M=1.22 * 10^{7}, S D=\right.$ $\left.1.12^{*} 10^{6}, N=3\right) \mathrm{t}(4)=3.39 * 10^{7}, \mathrm{p}=0.02$.

\subsection{Effect of pH Levels on Conidia Production of $M$. anisopliae Isolates}

$\mathrm{pH}$ values significantly affected conidia yield of the isolates on coffee husk (Table 4). The conidia harvest of AUMI1 and AUMI3 on coffee husk when the PH value adjusted to 4.5 was $2.77 \times 10^{7} \pm 0.23 \times 10^{7}$, and $3.35 \times 10^{7} \pm 0.23 \times 10^{7}$ conidia/gram of substrate respectively. AUMI2 
give its maximum conidia yield of $3.18 \times 10^{7} \pm 0.34 \times 10^{7}$ conidia/gram of substrate when treated on $3.5 \mathrm{pH}$. The highest mean of conidial harvest on tea waste was recorded by AUMI1 with 1.14 $\mathrm{x} 10^{7} \pm 0.11 \times 10^{7}$ conidia/gram of substrate. The overall conidia yield result record on AUMI2 and AUMI3 are not significantly varied among the tested $\mathrm{pH}$ values (Table 4).

Table 4. Effect of PH on conidia yield of M. anisopliae isolates under different substrates.

\begin{tabular}{|c|c|c|c|c|}
\hline \multirow[t]{3}{*}{ Substrate } & \multirow[t]{3}{*}{ pH } & \multicolumn{3}{|c|}{$\begin{array}{l}\text { Mean } \pm \text { SEM of conidia count at }\left(x 10^{7} \text { conidia/gram)for } P H\right. \\
\text { optimization after } 14 \text { days of incubation }\end{array}$} \\
\hline & & \multicolumn{3}{|c|}{ Metarhizium anisopliae Isolates } \\
\hline & & AUMII & AUMI2 & AUMI3 \\
\hline \multirow[t]{3}{*}{ Coffee husk } & 3.5 & $2.55 \pm 0.41^{(\mathrm{a})}$ & $3.18 \pm 0.34^{(\mathrm{a})}$ & $2.59 \pm 0.21^{(a)}$ \\
\hline & 4.5 & $2.77 \pm 0.02^{(b)}$ & $2.90 \pm 0.16^{(\mathrm{e})}$ & $3.35 \pm 0.23^{(b)}$ \\
\hline & 5.5 & $2.41 \pm 0.33^{(\mathrm{f})}$ & $2.03 \pm 0.20^{(i)}$ & $2.97 \pm 0.20^{(\mathrm{d})}$ \\
\hline \multirow[t]{3}{*}{ Tea waste } & 3.5 & $0.67 \pm 0.04^{(\mathrm{a})}$ & $0.59 \pm 0.17^{(b, c)}$ & $0.77 \pm 0.14^{(\mathrm{a})}$ \\
\hline & 4.5 & $1.14 \pm 0.11^{(\mathrm{c}, \mathrm{d})}$ & $0.88 \pm 0.05^{(\mathrm{f}, \mathrm{g})}$ & $0.76 \pm 0.08^{(\mathrm{c})}$ \\
\hline & 5.5 & $0.89 \pm 0.10^{(\mathrm{g}, \mathrm{h})}$ & $0.92 \pm 0.12^{(J)}$ & $0.69 \pm 0.11^{(\mathrm{f}, \mathrm{g})}$ \\
\hline \multirow[t]{3}{*}{ Wheat bran } & 3.5 & $1.19 \pm 0.39^{(\mathrm{a})}$ & $0.87 \pm 0.21^{(b)}$ & $2.26 \pm 0.37^{(\mathrm{a})}$ \\
\hline & 4.5 & $0.74 \pm 0.09^{(c)}$ & $0.98 \pm 0.35^{(\mathrm{f})}$ & $1.98 \pm 0.13^{(b, c)}$ \\
\hline & 5.5 & $0.96 \pm 0.05^{(\mathrm{g})}$ & $1.49 \pm 0.31^{(\mathrm{i}, \mathrm{J})}$ & $1.29 \pm 0.32^{(\mathrm{e}, \mathrm{f}, \mathrm{g})}$ \\
\hline \multirow[t]{3}{*}{ Vegetable } & 3.5 & $1.31 \pm 0.99^{(\mathrm{a})}$ & $0.98 \pm 0.23^{(b, d)}$ & $1.49 \pm 0.85^{(\mathrm{a})}$ \\
\hline & 4.5 & $0.44 \pm 0.19^{(\mathrm{c}, \mathrm{e})}$ & $1.72 \pm 0.31^{(\mathrm{f}, \mathrm{h})}$ & $2.87 \pm 0.61^{(b)}$ \\
\hline & 5.5 & $0.33 \pm 0.02^{(\mathrm{g}, \mathrm{i})}$ & $0.19 \pm 0.02^{(\mathrm{J}, \mathrm{k})}$ & $0.62 \pm 0.51^{(\mathrm{g})}$ \\
\hline
\end{tabular}

Note: Means in the same column within the same PH values designated by different letters are significantly different, (a-k), at $\mathrm{p} \leq 0.05$.

The $\mathrm{pH}$ test on vegetable wastes reduces the total conidial harvest record of all isolates from the records on moisture content and temperature determination. The optimal $\mathrm{pH}$ for conidia production of all fungal isolates fall between 3.5 and 4.5 (Table. 4). Isolate AUMI1 produce maximum conidia $1.31 \times 10^{7} \pm 0.99 \times 10^{7}$ conidia/gram of substrate at $\mathrm{pH} 3.5$ whereas isolates AUMI2 and AUMI3 produced $1.72 \times 10^{7} \pm 0.31 \times 10^{7}$ and $2.83 \times 10^{7} \pm 0.61 \times 10^{7}$ conidia/gram of substrate respectively, at $\mathrm{pH}$ 4.5. Compared to the conidia yield at the substrates natural $\mathrm{pH}$. Most of the tested $\mathrm{pH}$ values used in this study gives rise to the lowest conidia yield record in all substrates except on coffee husk. Coffee husk conidia productivity of all M. anisopliae isolates was increased when treated under the adjusted $\mathrm{pH}$ tests and the records of all treated $\mathrm{pH}$ levels was higher than the results treated on natural $\mathrm{pH}$ value of the substrate. The rest substrates were produced high conidial yield at their natural $\mathrm{pH}$ concentrations. 
The mean conidia yield of AUMI1 on coffee husk $\left(M=2.77 * 10^{7}, S D=4.32 * 10^{6}, N=3\right)$ was significantly higher from mean conidia yield on tea waste $\left(M=1.16^{*} 10^{7}, S D=1.93 * 10^{6}, N\right.$ = 3) $\mathrm{t}(2.77)=1.62 * 10^{7}, \mathrm{p}=0.01$. The mean conidia yield of AUMI2 on coffee husk $(M=$ $3.18^{*} 10^{7}, S D=5.86^{*} 10^{6}, N=3$ ) was significantly increased from mean conidia yield on tea waste $\left(M=9.23^{*} 10^{6}, S D=2.11^{*} 10^{6}, N=3\right) \mathrm{t}(2.51)=2.27 * 10^{7}, \mathrm{p}=0.01$. The mean conidia yield of AUMI3 on coffee husk $\left(M=3.35^{*} 10^{7}, S D=3.97 * 10^{6}, N=3\right)$ was significantly increased from mean conidia yield on tea waste $\left(M=7.70^{*} 10^{6}, S D=2.36^{*} 10^{6}, N=3\right) \mathrm{t}(3.26)=2.58^{*} 10^{7}$, $\mathrm{p}=0.002$.

\subsection{Effect of Inoculum Concentration on Conidia Production}

The highest level of conidia yields of AUMI1 $5.42 \times 107 \pm 0.57 \times 107$ conidia/gram of substrate on vegetable waste was achieved using $1 \times 105$ conidia $/ \mathrm{ml}$ inoculum concentration. The optimum conidia count of AUMI2 and AUMI3 was also recorded at 1x105 inoculum concentration on vegetable waste. The maximum conidia count per inoculum concentration was harvested at $1 \times 105$ conidia $/ \mathrm{ml}$ of inoculum on coffee husk. Conidia count record of the fungal isolates on wheat bran treated in all the inoculum concentrations were higher on 1x104 for AUMI1 and AUMI2 and on 1x105 for AUMI3.

Table 5. Effect of different inoculum concentrations on conidia yield of M. anisopliae isolates.

\begin{tabular}{|c|c|c|c|c|}
\hline \multirow[t]{3}{*}{ Substrate } & \multirow[t]{3}{*}{ Inoculum } & \multirow{2}{*}{\multicolumn{3}{|c|}{$\begin{array}{l}\text { Mean } \pm \text { SEM of conidia count at (x107 conidia/gram) for } \\
\text { Inoculum concentration optimization } \\
\text { Metarhiziumanisopliae Isolates }\end{array}$}} \\
\hline & & & & \\
\hline & & AUMII & $A U M I 2$ & AUMI3 \\
\hline \multirow[t]{3}{*}{ Coffee husk } & $1 * 10^{3}$ & $1.30 \pm 0.17$ & $0.75 \pm 0.18$ & $1.14 \pm 0.02$ \\
\hline & $1 * 10^{4}$ & $0.83 \pm 0.15$ & $0.95 \pm 0.04$ & $1.06 \pm 0.40$ \\
\hline & $1 * 10^{5}$ & $1.35 \pm 0.06$ & $1.32 \pm 0.02$ & $1.50 \pm 0.51$ \\
\hline \multirow[t]{3}{*}{ Tea waste } & $1 * 10^{3}$ & $0.64 \pm 0.12$ & $1.19 \pm 0.11$ & $0.40 \pm 0.18$ \\
\hline & $1 * 10^{4}$ & $0.88 \pm 0.005$ & $0.91 \pm 0.13$ & $0.20 \pm 0.03$ \\
\hline & $1 * 10^{5}$ & $0.63 \pm 0.19$ & $0.74 \pm 0.02$ & $0.26 \pm 0.06$ \\
\hline \multirow{3}{*}{ Wheat bran } & $1 * 10^{3}$ & $2.47 \pm 0.17$ & $0.89 \pm 0.01$ & $1.29 \pm 0.42$ \\
\hline & $1 * 10^{4}$ & $1.93 \pm 0.30$ & $1.47 \pm 0.33$ & $2.00 \pm 0.45$ \\
\hline & $1 * 10^{5}$ & $1.50 \pm 0.20$ & $1.14 \pm 0.34$ & $3.35 \pm 1.74$ \\
\hline \multirow[t]{3}{*}{ Vegetable waste } & $1 * 10^{3}$ & $0.55 \pm 0.20$ & $0.79 \pm 0.37$ & $0.82 \pm 0.03$ \\
\hline & $1 * 10^{4}$ & $0.79 \pm 0.07$ & $0.88 \pm 0.06$ & $1.07 \pm 0.14$ \\
\hline & $1 * 10^{5}$ & $5.42 \pm 0.57$ & $3.25 \pm 0.41$ & $4.63 \pm 0.53$ \\
\hline
\end{tabular}

The optimum inoculum concentrations for M. anisopliae isolates on vegetable waste were recorded at $1 \times 105$ conidia/ml. Inoculum concentration optimization test conducted on tea waste were also have different optimum concentrations for each isolate. AUMI1 were favored for maximum conidia productivity at $1 \times 104$ conidia/ml of inoculum concentration. The conidia 
count result $1.19 \times 107 \pm 0.11 \times 107$ conidia/gram of substrate and $0.40 \times 107 \pm 0.18 \times 107$ conidia/gram of substrate was recorded for AUMI2 and AUMI3 respectively at 1x103conidia/ml (Table 5).

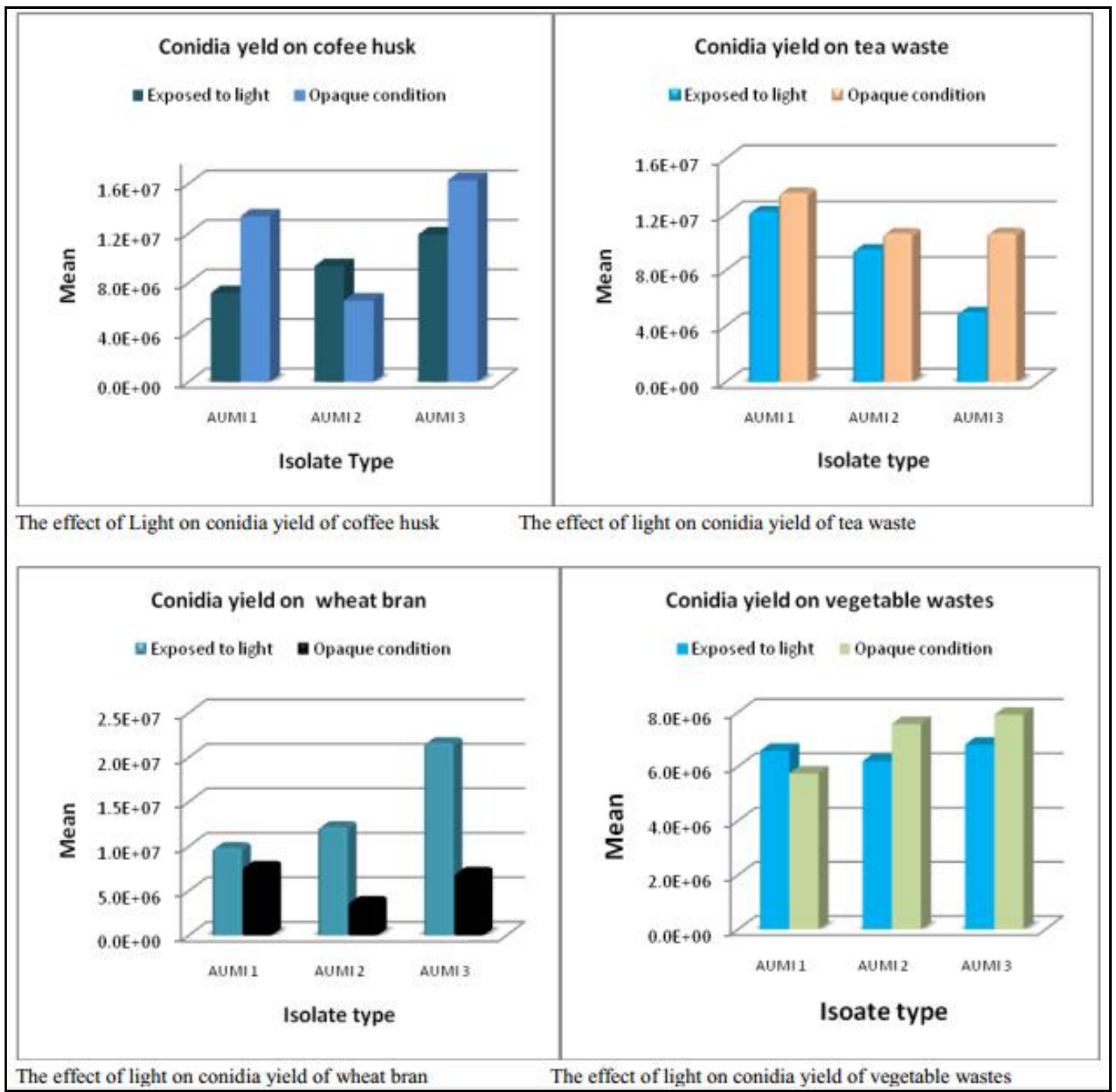

Figure 1. The effect of light on conidia yield of $M$. anisopliae isolates under different substrates.

\subsection{Effect of Light on Conidia Production of $M$. anisopliae Isolates}

The conidia yields of AUMI1 and AUMI3 in the absence of light were larger than in the presence of light on coffee husk. The substrate afforded comparatively higher conidia growth for AUMI1 and AUMI3 in opaque condition whereas in the presence of light for AUMI2. Excellent 
growths of all fungal isolates were afforded by the substrate tea waste at dark condition. It has been observed that the isolates, AUMI1 and AUMI2 was also produced higher conidia in the presence of light but, the maximum conidia yield was observed on cultures in the absence of light (Fig 1). Therefore, conidia production of the fungal isolates on tea waste was light independent when compared with wheat bran in which conidia productivity of all the fungal isolates were light intensive. The conidia production potential of vegetable waste under the presence and absence of light was evaluated as the results shown in figure 1 . The conidia production of AUMI1was light dependent whereas Opaque condition was favored for AUMI2 and AUMI3 to produce the highest conidia yield on vegetable wastes. Mean of the conidia yield was calculated from three replicates and each isolate was cultivated at $27^{0} \mathrm{C}$ for 14 days under sufficient light exposure and complete opaque condition as required.

\section{DISCUSSION}

Biological pest management using entomopathogenic fungi as microbial agents primarily requires mass production of the candidate on cheap cultivation media (Mohammed, 2006; Masoud et al., 2013). Different agricultural wastes were evaluated in this study as cheap potential substrates for conidia production of M. anisopliae isolates. All agricultural substrates were potential producers for high number of conidia even though difference in number was recorded among substrates. M. anisopliae isolate AUMI1, AUMI2 and AUMI3 was able to produce significantly high number of conidia $\left(4.90 \times 10^{7}, 3.74 \times 10^{7}\right.$ and $3.61 \times 10^{7}$ conidia/gram of substrate respectively) on vegetable wastes than their respective less productive substrates. Different vegetables contain different carbon and nitrogen source nutrients and their combination increases nutritional value of the substrate. Therefore, vegetables waste high productivity could be due to high macromolecular composition of lignocellulosic nutrients providing the necessary carbon and nitrogen source. Similarly, Herta et al. (2005); and Gao (2011) have indicated that combination of different carbon and nitrogen source resulted in high spore production.

Initial moisture content and water activity are the key factors in solid state fermentation reaction (Rajan and Nair, 2011). The availability of water strongly affects microbial growth. Therefore, the moisture content of the substrate should be within the suitable range. In the present study, the effects of various initial moisture contents were evaluated for all substrates. The best result for all $M$. anisopliae isolates was obtained at $60 \%$ moisture content on vegetable 
wastes and a comparable result of conidia count was also obtained at $80 \%$ on the same substrate. Therefore, the optimum moisture content $60 \%$ was obtained to grow isolates of $M$. anisopliae on vegetable wastes. Despite that, the optimum moisture content of other substrates required to conidiate each isolate varies as shown in Table 2 . When $35 \%$ of $1 \mathrm{~mm}$ size coffee husk favored AUMI1 and AUMI2 $\left(0.96 \times 10^{7} \pm 0.12 \times 10^{7}\right.$ conidia/gram and $1.62 \times 10^{7} \pm 0.44 \times 10^{7}$ conidia/gram respectively), $45 \%$ of the same substrate supports AUMI3. The results also revealed that, $1 \mathrm{~mm}$ size coffee husk was efficient in conidiation than the larger used in particle size. This may be due to difficulty to assimilate the larger in particle size by the enzymes secreted from the fungi. Overall coffee husks in the present study at any moisture content were less efficient in conidia production of all fungal isolates when compared to the other substrates. Similarly, (Zuriash Mamo and Tesfaye Alemu, 2012) have observed that the lowest conidia count of Trichoderma isolates was recorded on coffee husk under SSF technique.

The optimum moisture content of wheat bran to grow isolate AUMI3 (1.19 \pm 0.34 conidia/gram) and AUMI1, AUMI2 (1.46 ×10 $\pm 0.09 \times 10^{7}, 1.59 \times 10^{7} \pm 0.10 \times 10^{7}$ conidia/gram) are at $35 \%$ and $45 \%$ respectively. Conidia count reduction in high moisture content may be related to the fact that excess water occupies the space between particles of the substrate and restricts mass oxygen flow across (Pandey, 2003).

There was a gradual increment in conidia count record of AUMI1 and AUMI2 as moisture content increases from $35 \%$ to $80 \%$ on Tea waste. However, conidia count result of AUMI3 on the same substrate was higher at $45 \%$. Therefore, the highest conidia count record of AUMI1 and AUMI2 at $80 \%$ of moisture content was perhaps due to maximum water absorption capacity of the substrate. Pandey and Soccol (2001) have observed that the water absorption potential depends on factors such as solid matrix structure and superficial area, as well as the ability of hydrogen-bond formation sites, among others. As clearly indicated in table 2, the moisture content level of the substrate are not the only factors that affect conidia production, composition and structure of the substrate as well as the type of isolates cultivated are also determinants. Experiment that was conducted by Rosane et al. (2008) for comparison of conidia yield among different strains of Trichoderma on different substrate under the same moisture content results with no fungi growth and spore formation this assures that moisture content is not the only factor. 
Each isolate was incubated at 24,27 and $30^{\circ} \mathrm{C}$ to evaluate the effect of temperature on conidia production. Among others the substrates examined on vegetable wastes AUMI2 and AUMI3 (2.97 \pm 0.16 and $4.60 \pm 0.94$ conidia/gram of substrate respectively) were supported for maximum conidia yield at $30^{\circ} \mathrm{C}$ optimum temperature. However, vegetable waste also supported AUMI1 (5.05 \pm 0.43 conidia/gram of substrate) for maximum conidia yield at $27^{0} \mathrm{C}$ as an optimum temperature. The Ethiopian isolates of Metarhizium spp were also attained peak conidia production at $28^{0} \mathrm{C}$ (Seneshaw and Seyum, 2003). The high conidia productivity of wheat bran and vegetable wastes at $30^{\circ} \mathrm{C}$ was obtained perhaps due to water stress at a precise growth stage since high temperature causes loss of water via desiccation. Reynaldo and Sevastianos (2013) have clearly stated that water stress under SSF during the maximum growth period or biomass formation helps sporogenesis to start earlier and allows obtaining higher sporulation yield.

$\mathrm{pH}$ optimization test completely flipped conidial productivity potential of each substrate. The high conidia productive vegetable waste at natural $\mathrm{pH}$ levels of each substrate handovers to coffee husk. AUMI2 was produced the maximum conidia yield $\left(3.18 \times 10^{7} \pm 0.34 \times 107\right.$ conidia/gram) at $\mathrm{pH} 3.5$ on coffee husk. The optimum $\mathrm{pH}$ concentration for AUMI1 and AUMI3 was obtained at $\mathrm{pH} 4.5 \mathrm{using}$ coffee husk as substrate yielding $2.77 \times 10^{7} \pm 0.23 \times 10^{7}$, and 3.35 $\mathrm{x} 10^{7} \pm 0.23 \times 10^{7}$ conidia/gram respectively. Similarly, (Zuriash Mamo and Tesfaye Alemu, 2012) have reported that the optimum $\mathrm{pH}$ for conidia production of Trichoderma isolates was between 4.5 and 5.5. Except for coffee husk the overall conidia count record of the substrates on their natural $\mathrm{pH}$ was significantly higher than the initial $\mathrm{pH}$ value used for optimization. It is also important to mention that coffee husk high productivity was perhaps due to releasing of its organic matter after highly degraded by the $1 \mathrm{~N}$ of $\mathrm{HCl}$ (1 normality of hydrochloric acid) used to adjust $\mathrm{pH}$ at 3.5 into utilizable form by the candidate fungal isolates.

In the present study, conidiation of Metarhizium isolates of AUMI1, AUMI3 were best favored in the absence of light on coffee husk. The same was true for excellent conidia production of all isolates on tea waste when compared with wheat bran in which all the isolates were light dependent. Under exposure to light AUMI1 was high productive on vegetable wastes while, AUMI2 and AUMI3 requires opaque condition. Therefore, it is very important to keep in mind that light has essential effect on conidia production of Metarhizium isolates under SSF system on different substrates. 


\section{CONCLUSION}

From the study it is clear that all the evaluated substrates are capable to support growth of the Enthomopathogenic fungi $M$. anisopliae. Whereas, vegetable wastes showed to be the best candidate for conidia production. The fungal pathogens are abundantly found in soil and can be isolated using simple techniques and a selective medium. Mass conidial cultivation of these strains on vegetable wastes and applying to control crop loss due to swarm invasion of insect pests like Desert and migratory locust can be efficient and cost effective. Since, the use of chemical pesticides is not financially cheap and environmentally safe. In turn, biological control agents are effective against the target pathogen; they are eco-friendly; and do not affect ecological diversity of the farm. They are considered as excellent bio-control agents.

\section{ACKNOWLEDGEMENT}

We are truly grateful to Addis Ababa University School of graduate studies and the Department of Microbial, Cellular and Molecular Biology (DMCMB) for the help beyond the call of duty to financially and technically support the study.

\section{CONFICT OF INTEREST}

There are no conflicts of interests.

\section{REFERENCE}

Chen, Z.H., Xu, L., Yang, F. L., Ji, G. H., Yang, J \& Wang, J. Y. 2014. Efficacy of Metarhizium anisopliae isolate MAX-2 from Shangri-la, China under desiccation stress. BMC Microbiology, 14(4): 1-8.

Chinnadurai, S \& Ganesh, P. 2013. Isolation of Beauveria Bassiana, Classical Mutation And Solid Substrate Fermentation For Higher Biomass Production. Science Park Research Journal, 1(7):1-6.DOI: 10.9780/23218045/152013/23

Fatima, L. G.-P., Galán-Wong, L. J., López-Arroyo, J. I., Rodríguez-Guerra, R \& QuinteroZapata, I. 2013. Optimization of pathogenicity tests for selection of native isolates of Entomopathogenic fungi isolated from Citrus growing areas of Mexico on adults of Diaphorina citri kuwayama (Hemiptera: Liviidae). Florida Entomologist, 96(1): 187195. DOI: http://dx.doi.org/10.1653/024.096.0125 
Gao, L. 2011. A novel method to optimize culture conditions for biomass and sporulation of the entomopathogenic fungus beauveria bassiana IBC1201. Brazilian Journal of Microbiology, 42:1574-1584. ISSN: 1517-8382

Herta Stutz Dalla Santa, Osmar Roberto Dalla Santa, Débora Brand, de, L. P., Vandenberghe, S., \& Soccol, C. R. 2005. Spore production of Beauveria bassiana from Agro-industrial residues. Brazilian Archives of Biology and Technology an international journal, 48: 5160. ISSN 1516-8913

Holder, D. J \& Keyhani, N. O. 2005. Adhesion of the Entomopathogenic Fungus Beauveria (Cordyceps) bassiana to Substrata. Appled Environmental Microbiology, 71(9): 52605266. doi: 10.1128/AME.71.9.5260-5266.2005.

Jitendra, M., Kiran, D. J., Ambika, K., Priya, S., Neha, K \& Sakshi, D. 2012. Biomass Production of Entomopathogenic Fungi using various Agro Products in Kota Region, India. International Research Journal of Biological Sciences, 1(4): 12-16. ISSN 22783202.

Khan, M. Y \& Dahot, M. U. 2010. Effect of Various Agriculture Wastes and Pure Sugars on the Production of Single Cell Protein by Penicillium Expansum. World Applied Science Journal 8 (Special Issue of Biotech. \& Genet. Engineer.) : 80-84. ISSN 1818-4952.

Lord, J. C. 2005. From Metchnikoff to Monsanto and beyond: The path of microbial control. Journal of Invertebrate Pathology, 89: 19-29, doi: 10.1016/j.jip.2005.04.006.

Masoud, L., Rad, B., Amani, M \& Rahkhodaei, E. 2013. Mass production of entomopathogenic fungi Beauveria bassiana (Balsamo) by using agricultural products based on liquid- solid diphasic method for date palm pest control. International Journal of Agriculture and Crop Sciences, 5(19): 2337-2341.

Mohammed, E. D. 2006. Effect of Growing Media and Water Volume on Conidial Production of Beauveria bassiana and Metarhizium anisopliae. J. Biol. Sci.,, 6(2): 269-274.

Mudrončeková, S., Mazán̆, M., Nemcovic, M \& Salamon, I. 2013. Entomopathogenic Fungus species Beauveria bassiana (BALS.) and Metarhizium anisopliae (METSCH.) used as Mycoinsecticide effective in Biological contraol of IPS Typographus (L.). Jornal of Microbiology, Biotechnology and Food Sciences, 2(6): 2469-2472.

Muhammad Irfan, Muhammad Nadeem, Syed, Q \& Baig, S. 2012. Effect of Medium Composition on Xylanase Production by Bacillus subtilis using Various Agricultural 
Wastes. American-Eurasian Journal of Agricultural and Environmental Sciences, 12(5): 561-565.

Orzua, M. C., Mussatto, S. I., Contreras-Esquivel, J. C., Rodriguez, R., Garza, H. G \& Teixeira, J. A. 2009. Exploitation of agro industrial wastes as immobilization carrier for solid-state fermentation. Industrial Crops and Products, 30: 24-27, doi:10.1016/j.indcrop.2009.02. 001.

Pandey, A. 2003. Solid-state fermentation. Biochemical Engineering Journal, 13: 81-84.

Pandey, A \& Soccol, C. R. 2001. Solid-state fermentation in biotechnology: Fundamentals and applications. New Delhi, Asiatech.

Peng, G., Xie, L., Hu, J \& Xia, Y. 2009. Identification of genes that are preferentially expressed in conidiogenous cell development of Metarhizium anisopliae by suppression subtractive hybridization. Curr. Genet, 55: 263-271.

Pham, T. A., Kim, J. J \& Kim, K. 2010. Optimization of Solid-State Fermentation for Improved Conidia Production of Beauveria bassiana as a Mycoinsecticide. Mycobiology, 38(2): 137-143, doi: 10.4489/MYCO.2010.38.2.137.

Philip, M. N., Irungu, L. W., Ndegwa, P. N \& Maniania, N. K. 2011. Pathogenicity of Metarhizium anisopliae (Metch) Sorok and Beauveria bassiana (Bals) Vuill to adult Phlebotomus duboscqi (Neveu-Lemaire) in the laboratory. Journal of Vector Borne Diseases. 48: 37-40.

Rajan, A \& Nair, A. J. 2011. Comparative study on alkaline lipase production by a newly isolated Aspergillus fumigatus MTCC 9657 in submerged and solid-state fermentation using economically and industrially feasible substrate. Turk Journal of Biology, 35: 569574.

Rao, N. K., Hanson, J., Dulloo, M. E., Ghosh, K., Nowell, D \& Larinde, M. 2006. Manual of Seed Handling in Genebanks. Handbooks for Genebanks Maccarese, No. 8, ISBN978-929043-740-6.

Reynaldo, D. 1. C. Q \& Sevastianos, R. 2013. Challenges and opportunities of the bio-pesticides production by solid-state fermentation: filamentous fungi as a model. Critical Reviews in Biotechnology, 1-8.

Rosane, S. C., Helder, L. S. L., Pinto, G. A. S \& Carlos, A. T. G \& Rodrigues, S. 2008. Effect of Moisture on Trichoderma Conidia Production on Corn and Wheat Bran by Solid State Fermentation. Food Bioprocess Technol, 1: 100-104, doi: 10.1007/s11947-0034-x. 
Sahayaraj, K \& Namasivayam, S. K. R. 2008. Mass production of entomopathogenic fungi using agricultural products and by products. African Journal of Biotechnology,7(12): 19071910.

Seneshaw, A \& Seyum, E. 2003. Evaluation of Ethiopian isolates of Entoopathogenic fungi as potential biological control agents of the desert locust (Schistocerca gregaria) pest management, Addis Ababa University College of Natural Sciences: 1-73.

Wang, C \& Powell, J. E. 2002. Isolation and Evaluation of Beauveria bassiana for Control of Coptotermes formosanus and Reticulitermes flavipes (Isoptera: Rhinotermitidae). Sociobiology, 41(1): 1-13.

Wu, J., Ali, S., Huang, Z., Ren, S \& Cai, S. 2010. Media Composition Influences Growth, Enzyme Activity and Virulence of the Entomopathogen Metarhizium anisopliae (Hypocreales: Clavicipitaceae). Pakistan Journal of Zoology, 42(4): 451-459, doi: 00309923/2010/0004-0451

Yadav, S \& Neeraj, 2012. Beauveria bassiana (Bals.-Criv.) Vulliemin- Use as a magical biocontrol agent.. International Journal of Advanced Biological Research, 2(1): 159-162.

Zhang, W., Qiu, L., Gong, A., Cao, Y \& Wang, B. 2013. Solid-state Fermentation of Kitchen Waste for Production of Bacillus thuringiensis- based Bio-pesticide. Bio Resources, 8(1): 1124-1135.

Zuriash Mamo and Tesfaye Alemu. 2012. Evaluation and Optimization of agro- industrial wastes for conidial production of Trichoderma isolates under solid state fermentation. Journal of Applied Biosciences, 54: 3870-3879. 